\title{
On the Problem of Nesting Trees Preferred by Milvus migrans in The Forest Belts of The South of Western Siberia
}

\author{
Roman Fedorovich Bakhtin \\ The Shukshin Altai State Academy of Education, 53, Korolenko Street, \\ Biysk, Altai Territory, 659333, Russian Federation.
}

DOI: http://dx.doi.org/10.13005/bbra/1920

(Received: 12 August 2015; accepted: 06 October 2015)

\begin{abstract}
The paper presents the data about Black Kite nesting in forest belts in the South of Western Siberia in the Altai territory. The length of the studied plantations was $50 \mathbf{~ k m}$. In the study, 72 nesting trees of this predator were identified. Black Kites' preferences in selecting the specie of testing trees, its ontogenetic state, trunk thickness and tree strength were tested with the use of Ivlev-Jacobs selectivity index. The results have showed that the most preferred for nesting tree species in forest belts are poplar Populus sp. (selectivity index 0.5), birch Betula sp. occupied in proportion to their abundance (-0.02), while pine Pinus silvestris and maple Acer sp. are ignored to various degrees. By the ontogenetic state, middle-aged generative trees $(0.74)$ are preferred, and old generative trees $(-0.18)$ are ignored to a certain degree. In respect to the diameter of nesting trees' trunks, trees 31$40 \mathrm{~cm}$ in diameter are preferred (0.23). In proportion to their abundance, trees $21-30 \mathrm{~cm}$ in diameter are used (-0.04). Trees with other trunk thickness are ignored to various degrees, up to being totally avoided. The most preferred for nesting in forest belts are the trees with the index of power of 1.6-2 (0.31). Trees with the index of 1.1 to 1.5 , and 2.1 to 2.5 are used approximately in proportion to their abundance $(-0.02$ and $-0,07$, respectively), and trees with the values of this index more than 2.6 and less than 1 are almost or completely ignored.
\end{abstract}

Key words: Black Kite, nesting tree, the Ivlev-Jacobs selectivity index, forest belt, ontogenetic state, trunk diameter, index of power.

Since ancient times, people have been transforming the natural landscapes for their economic needs. Their reduction and emergence of new anthropogenic territories has forced many bird species to reduce their population. However, some taxa with wide ecological opportunities were not only able to adapt, but to increase their population.

Currently, agricultural landscapes are an integral part of the natural-anthropogenic environment. Forest belts, being mandatory units of the farmland, have proliferated, since they

\footnotetext{
* To whom all correspondence should be addressed.
}

feature the necessary set of soil protection features. Over time, they were assimilated by representatives of groups of birds of prey and owls, such as Black Kite Milvus migrans, common buzzard Buteo buteo, common kestrel Falco tinnunculus, and long-eared owl Asio otus.

\section{Characteristics of the studied area}

The studied area is located in the South of Western Siberia, within the Altai territory. A considerable share of the material was collected in the territory of the Biysk district located in the Southeastern part of the region, and covering the area of $2,173 \mathrm{~km}^{2}$.

The contemporary appearance of the terrain in the Biysk district is mainly determined by the Biya River valley, which separates the two major 
morphostructures - the Biya-Chumysh upland in the North, and the Pre-Altai plain in the South. The absolute altitude of the Biya-Chumysh upland within the studied area is $390 \mathrm{~m}$ above sea level (mnt. Ploskaya). It is characterized by broad ridges up to $50 \mathrm{~m}$ high, split with ravines with gentle slopes and flat bottom ${ }^{1}$. The terrain of the interfluve area between the Biya and Katun rivers within the Biysk district is in general plain, transforming into hilly to the East - at the point of contact with the North-Eastern foothills of the Altai uplands.

The natural and climatic features of the studied area are determined by it being geographically located in the center of the Eurasian continent, in the zone of continental climate of the temperate latitudes. The average minimum temperature is $-23.3^{\circ} \mathrm{C}$; and the absolute minimum is $-54^{\circ} \mathrm{C}$ in January. The average temperature in July is $+19.2^{\circ} \mathrm{C}$, the maximum average temperature is $25.9^{\circ} \mathrm{C}$, the absolute maximum is $+41^{\circ} \mathrm{C}$, and the minimum is $+2^{\circ} \mathrm{C}$. The annual precipitation is $450-$ $500 \mathrm{~mm}^{1}$.

\section{The material and the methods of the study}

The study was performed during the field seasons in years 2014-2015, in the Southeast of the Altai territory. In the studied area, Black Kites have assimilated protective forest belts to a greater extent, as compared to other species of the birds of prey. Field work was performed in spring and in autumn, when the trees are devoid of foliage, which considerably increased productivity in searching for nests. During the study, the observers moved in a car, or walked along the forest belts, and all found nests of Black Kites were recorded using a GPS navigation system for subsequent statistical processing. During the period of study, $50 \mathrm{~km}$ of forest belts have been studied, and 72 nests of this predator have been identified (Fig. 1), mainly in plantations of the single tree specie, poplar Populus sp. The species belonging of the nesting structures were determined visually by direct and indirect evidence - the nature of the nest structure, the presence of anthropogenic materials (in, around and under the nest), characteristic food debris and rangles, feathers, etc., or by the presence of adult birds close to the occupied nests. The nests' pertinence to a particular nesting site was determined by visiting them during the nesting season.
The basis for processing the material about nesting preferences of Black Kites was the method of M. S. Romanov [2, 3]. In studying the nesting territories, the spatial structure of the forest stand was studied within the radius of $20 \mathrm{~m}$ from the nesting tree (the number of trees of each specie was counted). In studying the nesting trees of Black Kites, their parameters were compared to the parameters of the four nearest trees in the first tier of the tree stand. To do so, the space around the nesting tree was divided into four equal sectors oriented to the cardinal directions, and the nearest tree to the nesting one was measured in each of them ${ }^{2,3}$.

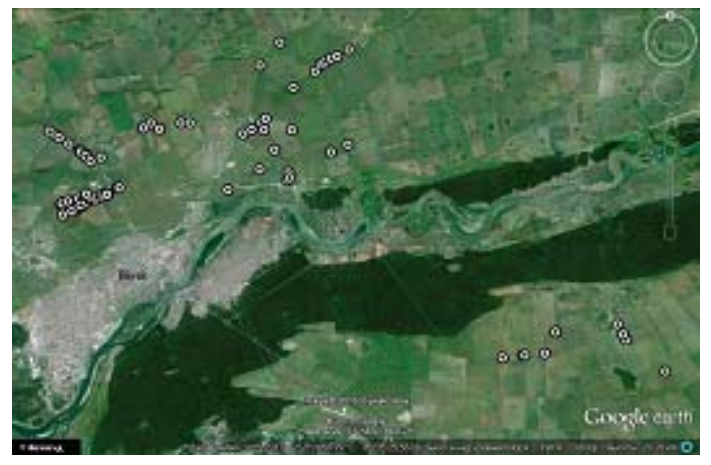

Fig. 1. Nests of Black Kites Milvus migrans identified in forest belts in the Biysk district of the Altai territory A scale of plants' ontogenetic states was used to describe the nesting trees and the trees nearest to them [4]. Strength of the trees and development of their crowns were assessed by the index of power, i.e., the ratio of trunk diameter in centimeters $1.3 \mathrm{~m}$ above the ground to the height of the tree in meters ${ }^{2}$. For the purpose of describing the nesting trees, their size, nest altitude, nest location relative to the crown, and the nature of its placement in the tree were analyzed. Black Kites' selectivity of various parameters of nesting and neighboring trees was assessed with the use of the Ivlev-Jacobs selectivity index. The index is based on comparing the share of the resource in the spectrum of the resources used by the bird and the share of this resource in the environment ${ }^{2,3}$.

The statistical data was processed in the Statistica 6.0 application. By the parameters of the nesting trees, the collected field materials were checked for normality using the Shapiro-Wilk test. 


\section{RESULTS}

The distance between the nesting structures of different pairs of Black Kites $(n=43)$ in neighboring nesting areas in forest belts ranged between 180 and 1,429 m, averaging 538 $\pm 54.1 \mathrm{~m}$ (Fig. 2). This distance should not be taken as the distance between the nesting pairs, since some nesting areas may remain empty or be abandoned in different years.

The distances gap between 400-600 and $800-1,200 \mathrm{~m}$ (Fig. 2) is explained by the fact that in the same forest belt, the nests are located on average about $500 \mathrm{~m}$ from each other, and the distance between the adjacent nests in different forest belts often exceeds 1,000 m.

Over half of the nests of Black Kites - 44 (61.1\%) in case of nesting in forest belts were located in poplars, 14 nests (19.4\%) were located

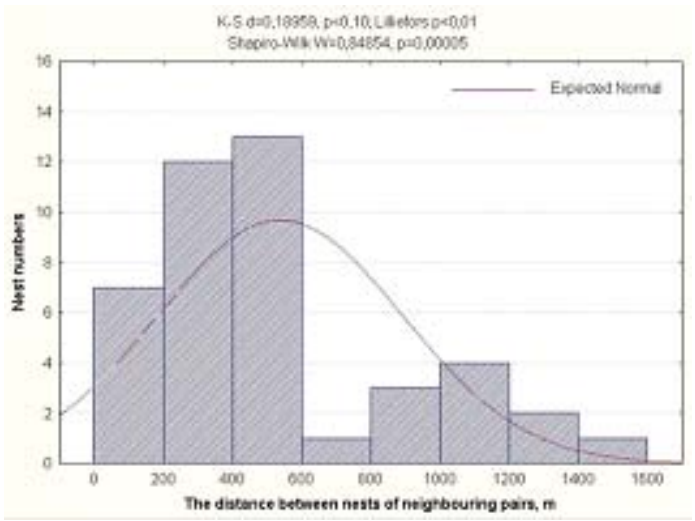

Fig. 2. Distribution of nests of Black Kite Milvus migrans by the distance between them

The height of nesting trees used by Black Kites as a substrate for building nests in forest belts ranged between 7 and $32 \mathrm{~m}$, on the average amounting to $19.9 \pm 0.66 \mathrm{~m}(\mathrm{n}=72)$; the height of nests above the ground is 5 to $20,10.0 \pm 0.37 \mathrm{~m}$ on the average $(n=72)$. In relation to the crown of trees, the kites' nests were located as follows: $48.6 \%$ in the bottom part, $31.9 \%$ in the middle part, $8.3 \%$ in the upper part, and $11.1 \%$ under the crown $(n=72)$. By the arrangement in the tree, nests $(n=72)$ were located: in the fork of the trunk $-55.6 \%$, at the base of lateral branches of first tier $-31.9 \%$, on inclined trunk $-6.9 \%$, on branches away from the in birches Betula sp., 6 (8.3\%) - in maples Acer sp., 4 (5.6\%) - in pines Pinus silvestris, 2 (2.8\%) in apple trees Malus sp., and 2 (2.8\%) - in elms Ulmus parvifolia ${ }^{5,6}$. In order to identify the preferences of Black Kites in choosing the tree species for nesting in mixed forest belts, the Ivlev-Jacobs selectivity index was used, and a curve of the index to specie dependence was made (Fig. 3) (31 nesting trees, 124 neighboring trees). The calculations did not include the nests located in apple trees and elms, since kites occupied and rebuilt old nests of corvids (Corvidae), and the trees of these species are isolated in forest belts.

Analysis of the selectivity index (Fig. 3) shows that most attractive for nesting of Black Kites in mixed forest belts are poplars (the IvlevJacobs index 0.5), birches are chosen in proportion to their abundance (-0.02), while pines and maples are ignored to varying degrees.

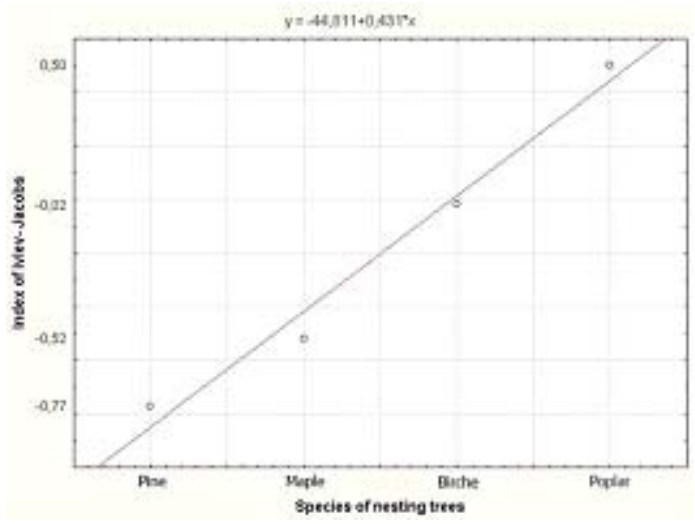

Fig. 3. Selectivity of Black Kites Milvus migrans in respect of specie of the nesting tree in case of nesting in mixed forest belts

trunk $-4.2 \%$, and in the crack of the trunk $-1.4 \%^{5}$. It is widely known ${ }^{2,7,8,9}$ that most species of birds of prey living in forests prefer to nest in most aged trees. However, some authors ${ }^{2}$ attribute this not only to the age of the tree, but to its ontogenetic status as well. According to the scale of ontogenetic states ${ }^{4}$, all kinds of trees pass several consecutive phases in their development, from seedlings to old generative and senile trees. The generative period of the trees, in turn, is divided into the following ontogenetic status: generative young, middle-aged and old generative trees. In the studied area, 72 nesting trees were 
detected, with 45 being middle-aged generative, and 27 - old generative (Table 1). The ontogenetic state of the neighboring nesting trees is shown in Table 1.

Table 1. The ontogenetic status of nesting trees for Black Kite Milvus migrans and the four nearest trees, \%

\begin{tabular}{lcc}
\hline The state of the tree & $\begin{array}{c}\text { Nesting trees } \\
(\mathrm{n}=72)\end{array}$ & $\begin{array}{c}\text { Trees adjacent to the } \\
\text { nesting ones }(\mathrm{n}=288)\end{array}$ \\
\hline Young generative & - & 3.8 \\
Mid-aged generative & 62.5 & 76.4 \\
Old generative & 37.5 & 19.8 \\
\hline
\end{tabular}

Analysis of the selectivity of the Black Kites that nest in forest belts with regard to the ontogenetic state of the trees was performed on the basis of comparing the nesting trees $(n=72)$ and the trees adjacent to them $(n=288)$. The obtained results show that generative middle-aged trees are preferred, and old generative trees are avoided to a certain degree (the Ivlev-Jacobs selectivity index 0.74 and -0.18 , respectively), while young generative trees were completely avoided (Table 1). Probably, the fact that Black Kites prefer medium-aged trees rather than old ones in forest belts can be explained by the fact that most of them are poplars, which become more fragile with age, and the architectonics of the crown is probably less convenient for nesting.

It is believed that generally the diameter of nesting trees' trunks is larger than that of the surrounding trees ${ }^{2}$. The diameter of Black Kites' nesting trees' trunks (about $1.3 \mathrm{~m}$ above the

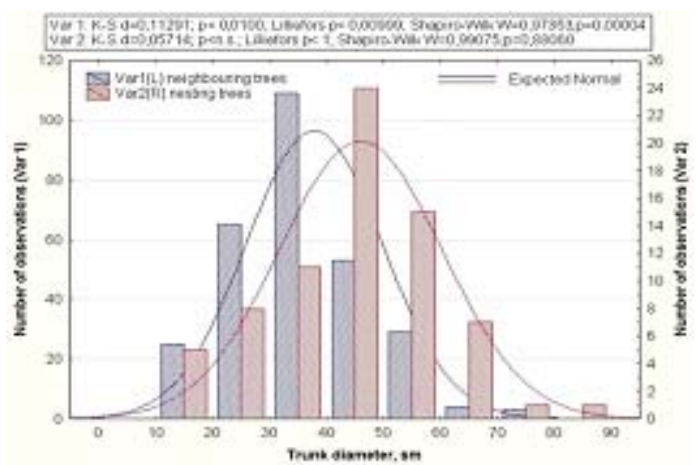

Fig. 4. Distribution of nesting trees diameters for Black Kite Milvus migrans and adjacent trees ground) in forest belts is 13 to 81 , averaging $45.8 \pm 1.68 \mathrm{~cm}(\mathrm{n}=72)$ and of trees adjacent to the nesting trees is 14 to 77 , averaging $37.7 \pm 0.70 \mathrm{~cm}$ $(\mathrm{n}=288$ ), which proves this assertion (Fig. 4).

Black Kites' preferences to the diameter of the trunk of nesting trees was determined with the use of the Ivlev-Jacobs selectivity index, and a curve of the index to trunk dependence was built (Fig. 5). Trees diameters were divided into 7 ranks. The curve shows that, despite the fact that the average trunk diameter of nesting trees is $45.8 \mathrm{~cm}$, kites prefer trees 31 to $40 \mathrm{~cm}$ thick (the selectivity index is 0.23 ). Approximately in proportion to their abundance, trees 21 to $30 \mathrm{~cm}$ thick (-0.04) are used by this predator. Trees of different thickness are ignored to various degrees, up to avoiding totally. Data calculation for the curve did not include the only nesting tree with the trunk $81 \mathrm{~cm}$ in diameter, since no trees of similar size were found in the proximity of the nesting trees.

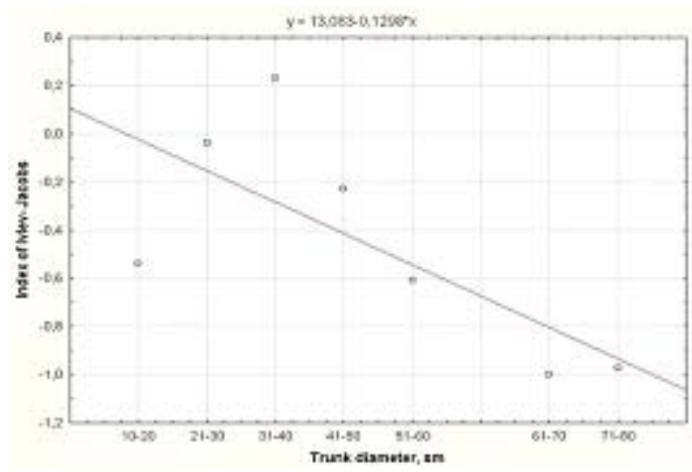

Fig. 5. Selectivity of nesting trees diameter by Black Kites Milvus migrans in nesting in forest belts 
In studying the nesting preferences of Black Kites in forest belts, we also considered the index of power of the trees $(\mathrm{Ip}=\mathrm{D} 1.3 / \mathrm{H})$. The index of power for nesting trees was 1.2 to 5.0 , averaging $2.4 \pm 0.08(\mathrm{n}=72)$, for the neighboring trees -0.6 to 5.0, averaging $2.0 \pm 0.04(\mathrm{n}=288)$. Predominance of the index of power of nesting trees, as compared to the neighboring ones, with regard to the birds of prey is confirmed by studies of other authors ${ }^{2,10}$

The use of the Ivlev-Jacobs selectivity index to the strength of the trees (Fig. 6) showed that the most preferred for nesting in forest belts were the trees with the index of power of 1.6-2 (0.31). The trees with the index of 1.1 to 1.5 and 2.1 to 2.5 are used for nesting approximately in proportion to their abundance $(-0.02$ and -0.07 , respectively). The trees with the index of more than 2.6 and less than 1 are almost completely or completely ignored.

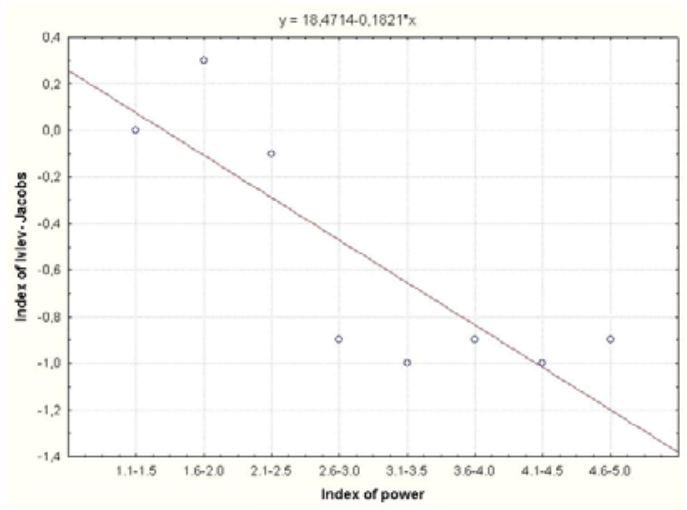

Fig. 6. Selectivity of nesting trees strength by Black Kites Milvus migrans in nesting in forest belts

The index of power of about 4 or more are, as a rule, related to maple trees, where kites nest as well, but these trees are rarely used as the substrate for nests.

\section{CONCLUSION}

In the studied area, the field protective shelter belts are an integral part of the surrounding landscape. Currently, birds of prey, including Black Kites, actively use them as nesting habitats. The choice of trees used by kites as a substrate for nest is affected by several factors, mainly by the size and type of the tree. It has been found that for nesting in forest belts, the most preferred specie is poplar (the Ivlev-Jacobs selectivity index equal to $0.5)$. By the ontogenetic status, middle-aged generative trees are chosen (the index is 0.74 ). The preferred diameter of the trunk of nesting trees is $31-40 \mathrm{~cm}$ (the index is 0.23 ), and the index of power is 1.6-2 (index is 0.31 ). Our findings are not always consistent with simple averaging of the studied parameters, which fact confirms correctness of using the selectivity index for studying resources and their shares used by the birds in life activities.

Obviously, in other nesting habitats in the studied area, such as pine forests, floodplain forests and separated forest stands, preferences of Black Kites in choosing nesting trees may be different.

\section{REFERENCES}

1. Baklanova, S.L., Geography of the Altai territory. Local history lessons. Study guide. Biysk: The "Biy" publishing house, 2008; 288.

2. Romanov, M.S., Topical relations of forest birds of prey in the mosaics of the vegetative cover. Thesis of Candidate of Biol. Sciences, the Moscow State Pedagogical University, Moscow, 2001; 225.

3. Romanov, M.S., Birds of prey and black storks in the vegetation of Nerusso-Desna woodlands. Study and preservation of the biological diversity of the Bryansk region. Materials for keeping the Red Book of the Bryansk region, Issue 1. Trubchevsk, 2005; 190-210.

4. Diagnoses and keys of ontogenetic states of the trees, Moscow: the Moscow State Pedagogical Institute, 1989; 40.

5. Bakhtin, R.F., To the issue of Black Kite nesting in forest belts. Successes in Modern Natural Science, 2014; 5: 190.

6. Bakhtin, R.F., Black Kite in the anthropogenic landscapes: a monograph. Biysk, 2013; 123.

7. Galushin, V.M., The number and territorial distribution of birds of prey in the European center of the USSR. Proceedings of the Oka Natural reserve, 1971; 8: 5-132.

8. Ivanovsky, V.V., Rare birds of prey of the Belorussian lake district and the methods of their protection. Thesis of Candidate of Biol. Sciences, Moscow, 1985; 250.

9. Shepel, A.I., Birds of prey and owls of Perm Kama region. Irkutsk, 1992; 296.

10. Novikova, L.M., The population and distribution of common buzzards in the Kerzhenets State Nature Reserve, Russia. Birds of Pray and their Preservation, 2009; 16: 139-150. 